\title{
Clinical and Biochemical Changes in Polycystic Ovarian Syndrome Patients in Response to 3 Different Oral Hypoglycemic Drugs: A Double Blind Randomized Controlled Study
}

\author{
Ahmed S. El-Halwagy, Adel A. Al-Gergawy, Engy S. Eleslam, Enaam S. Abd Elbar \\ Faculty of Medicine, Tanta University, Tanta, Egypt \\ Email: halwagy22@yahoo.com
}

How to cite this paper: El-Halwagy, A.S., Al-Gergawy, A.A., Eleslam, E.S. and Abd Elbar, E.S. (2017) Clinical and Biochemical Changes in Polycystic Ovarian Syndrome Patients in Response to 3 Different Oral Hypoglycemic Drugs: A Double Blind Randomized Controlled Study. Open Journal of Obstetrics and Gynecology, 7, 117-128. http://dx.doi.org/10.4236/ojog.2017.71013

Received: January 2, 2017

Accepted: January 15, 2017

Published: January 18, 2017

Copyright $\odot 2017$ by authors and Scientific Research Publishing Inc. This work is licensed under the Creative Commons Attribution International License (CC BY 4.0).

http://creativecommons.org/licenses/by/4.0/

(c) (i) Open Access

\begin{abstract}
Introduction: This study was done to evaluate other oral hypoglycemic medications; especially the new ones in the management of PCOS patients as alternatives to the standard medication used for this purpose Metformin. Patients and Methods: 105 patients were enrolled and randomly distributed into 3 groups according to sequence of computer-generated block-random numbers. Each group included 35 patients. This randomized double blind case controlled study was conducted at Tanta University Hospital from December 1, 2015 to October, 1, 2016. In group A (study group 1) the patients received Pioglitazobe $30 \mathrm{mg}$ once a day for 6 months while in group B (study group 2) the patients received Vildagliptin $50 \mathrm{mg}$ once daily. In Group C (control group) the patients received Metformin $500 \mathrm{mg}$ tds. for 6 months. The clinical outcome measures of the study were the improvement in the regularity of the menstrual cycle, the BMI and the improvement in the modified Ferriman-Gallwey (F-G) score for hirsutism. The biochemical outcome measures will be the change in the Serum Free testosterone, dehydroepiandrosterone (DHEA), fasting insulin level, Glcosylated hemoglobin ( $\mathrm{Hb} \mathrm{A1c}$ ) and fasting Low Density Lipoproteins (LDL) levels. Results: Pioglitazobe in the study group 1 patients showed a significant reduction of BMI $(p=0.016)$, Ferriman-Gallwey score $(p=0.003)$, free testosterone level $(p=0.003)$, DHEA level $(p=0.001)$, fasting insulin level $(p=0.036)$ and $\mathrm{Hb}$ alc level $(p=0.000)$, and also significant reduction of menstrual irregularities $(p=0.035)$. When compared to Metformin in the control group 3, there were significant reduction of BMI $(p=0.010)$, Ferriman-Gallwey score $(p=0.002)$, free testosterone level $(p=0.034), \mathrm{Hb}$ alc $(p=0.000)$ level and significant reduction of menstrual irregularities $(p=0.004)$ only. This means that the clinical and metabolic effect of Pioglitazobe is better than Metformin in PCOS patients. On the contrary there were disappointing results of the new drug Vildagliptin in group 2; the patients in this group
\end{abstract}


showed significant reduction of BMI $(p=0.001)$, Ferriman-Gallwey score $(p=0.046)$ and $\mathrm{Hb}$ alc $(p=0.000)$ level only. Non significant effect on menstrual irregularities and non significant reduction of LDL level are noticed. But there is elevation of Ferriman-Gallwey score, free testosterone level, DHEA level and fasting insulin level. Conclusion: Pioglitazobe is an effective and safe alternative to Metformin in the management of PCOS patient although further studies including larger number of patients should be done while Vildagliptin should be omitted for use in PCOS patients.

\section{Keywords}

PCOS, Pioglitazobe, Vildagliptin, Metformin

\section{Introduction}

Polycystic ovary syndrome is one of the most common endocrinopathies, with $5 \%-10 \%$ incidence among women in the child bearing age [1]. PCOS is diagnosed by diverse manifestations including chronic anovulation or oligo-ovulation, hyperandrogenism (clinical or biochemical) and polycystic ovaries seen by ultrasound [2]. PCOS is the most prevalent etiological factor of female infertility and is also associated with increased risks of diabetes mellitus, cardiovascular disorders, and endometrial cancer [3]. Although it is not yet fully understood, insulin resistance and its compensatory hyperinsulinemia are thought to play a key role in the pathogenicity of PCOS [2] [3]. The incidence of insulin resistance in PCOS is substantially higher in weight- and agematched women without PCOS [4] and is a consistent feature of PCOS in both normal and overweight women. Insulin resistance also appears to play a significant role in the pathogenesis of the hyperandrogenism and infertility of PCOS [5]. Women with anovulation, hyperinsulinemia, and hyperandrogenism are at greater risk of developing diabetes with an age of onset 30 years earlier than in the general population [6]. Hyperinsulinemia increases the risk of cardiovascular disease both directly and by its impact on lipid metabolism [7].

Insulin sensitizers are an alternative therapeutic way to the treatment of PCOS [6]. Although Metformin and Pioglitazobe reduce insulin resistance, they have different pharmacodynamics [8]. Metformin is a biguanide, which decreases hepatic glucose production, circulating insulin and intestinal glucose absorption, and improving peripheral tissue utilization of glucose. Pioglitazobe is a peroxisome proliferator-activated receptor gamma agonist which enhances the ability of muscles to metabolize glucose and improves insulin sensitivity without hypoglycemia [9] [10].

Vildagliptin is a strong and selective inhibitor of dipeptidyl peptidase-4 (DPP-4) that improves blood glucose control in type II DM by enhancing $\alpha$ - and $\beta$-cell response to glucose [11].

Multiple clinical studies proved that Vildagliptin improves blood glucose control in patients with type II DM when given as sole agent [12], or when given in combination with other antidiabetic medications, or with insulin [13]. Treatment with Vildagliptin has proven to have good overall safety profile [14] [15]. 


\section{Patients and Methods}

This study was conducted in the Department of Obstetrics and Gynecology, Tanta University on patients attending the outpatient clinic. The study was held in the period from December 1, 2015 to October, 1, 2016. The number of patients enrolled in the study was 105 patients after application of inclusion and exclusion criteria.

All women were thoroughly informed about the study aims and through discussion about the procedure, associated benefits and risks and assigned written consent.

\subsection{Inclusion Criteria}

The study inclusion criteria were: Age from 18 to 30 years, with diagnosed PCOS according to Rotterdam criteria [16] i.e. the presence of at least 2 of the following 3 criteria: 1) Oligo/anovulation, 2) clinical or biochemical signs of hyperandrogenism including hirsutism, acne, or increased serum Free testosterone, and 3) polycystic ovaries by ultrasound. Only the patients attending our clinics for PCOS symptoms other than infertility; namely obesity, hirsutism and menstrual irregularities will be included in this study.

\subsection{Exclusion Criteria}

The exclusion criteria were patients presented by DUB, patients with diabetes mellitus, abnormal liver function tests, known cardiac or renal disease, endocrinological diseases, chronic diseases, smoking, and also patients with infertility complains, suspicious of benign or malignant ovarian condition (indicated by ultrasound or proved by histopathology) were excluded from this study. In addition, of using of oral contraceptive drugs and other drugs related with ovarian function at least 3 months before research.

\subsection{Baseline Examination}

All patients were assessed by history taking, clinical examinations and were investigated by routine investigation to check for general condition. Patients were evaluated for hirsutism at baseline and at the end of the study using the modified Ferriman-Gallwey (F-G) score [17]. Women with an F-G value of 8 or greater were considered to be hirsute. Abdominal and Ultrasound was done to confirm diagnosis of PCOS and to check for other pelvic pathology.

\subsection{Biochemical Assay}

Fasting Serum (free testosterone, dehydroepiandrosterone (DHEA) and, insulin leves) were assessed by automated enzyme immune system AIA -1800st "TOSOH Bioscience". Glycosylated hemoglobin (Hb A1c) was assessed by HPLC (ADAMSTM"AIC HA-8180T (arkary), and $\geq 12$ hours Fasting Serum Low Density Lipoproteins (LDL) levels calculation by Friedewald equation (SPINREACT cholesterol \& triglyceride Kits).

The 105 patients included in the study were randomized in 3 study groups according to sequence of computer-generated block-random numbers. Neither the researchers nor the participants will know their study group.

In group A (study group 1) (35 patients) the patients received Pioglitazobe $30 \mathrm{mg}$ once a day for 6 months while in group B (study group 2) (35 patients)the patients received Vildagliptin $50 \mathrm{mg}$ once daily for 6 months. In Group C (control group) (35 pa- 
tients) the patients received Metformin $500 \mathrm{mg}$ tds. for 6 months.

The clinical outcome measures of the study were the improvement in the regularity of the menstrual cycle, the BMI and the improvement in the modified Ferriman-Gallwey (F-G) score for hirsutism. The biochemical outcome measures will be the change in the Serum free testosterone, dehydroepiandrosterone (DHEA), fasting insulin level, Glcosylated hemoglobin (Hb A1c) and Low Density Lipoproteins (LDL) levels.

\subsection{Sample Size Calculation}

Power analysis for a dependent sample $t$-test was conducted in $\mathrm{G}^{*}$ Power to determine a sufficient sample size using an alpha of 0.05 , a power of 0.80 , a medium effect size ( $d z=$ 0.5 ), and two tails [18]. Based on the aforementioned assumptions, the desired sample size is 34 in each study arm.

All statistics were performed using MinitabVer.17 (Minitab Inc., USA).

\section{Results}

On comparing demographic, clinical and biochemical data of the study groups using one way ANOVA (Table 1 ) there was no significant difference (all $p$ values are $>0.05$ ). Assessment of the effect of the drug Pioglitazobe on the study variables in group 1 (Table 2) using paired T test shows significant reduction of BMI, Ferriman-Gallwey score, free testosterone level, DHEA level, Fasting insulin level and $\mathrm{Hb}$ alc level. But non significant reduction of LDL level is noticed.

Table 3 shows the effect of Pioglitazobe on the menstrual irregularities in group 1, Chi Square test shows significant reduction of oligomenorrhea and amenorrhea i.e. significant regaining of menstrual cyclicity.

Assessment of the effect of the drug Vildagliptin on the study variables in group 2 (Table 4) using paired $\mathrm{T}$ test shows significant reduction of $\mathrm{BMI}$ and $\mathrm{Hb}$ alc level. Non significant reduction of LDL level is noticed. But there is elevation of Ferriman-Gallwey score, free testosterone level, DHEA level and Fasting insulin level.

Table 1. Comparison of the Pre-study variables between the 3 groups.

\begin{tabular}{|c|c|c|c|c|}
\hline & $\begin{array}{c}\text { Group } 1 \\
\text { Pioglitazobe }\end{array}$ & $\begin{array}{c}\text { Group } 2 \\
\text { Vildagliptin }\end{array}$ & $\begin{array}{c}\text { Group } 3 \\
\text { Metformin }\end{array}$ & $p$ value \\
\hline Age & $25.5 \pm 4.0$ & $24.5 \pm 3.6$ & $23.2 \pm 4.3$ & 0.058 \\
\hline BMI & $27.5 \pm 5.2$ & $28.0 \pm 5.1$ & $25.8 \pm 5.7$ & 0.199 \\
\hline $\begin{array}{l}\text { Ferriman-Gallwey } \\
\qquad(F-G) \text { score }\end{array}$ & $12.0 \pm 7.4$ & $11.8 \pm 7.9$ & $12.3 \pm 7.4$ & 0.961 \\
\hline $\begin{array}{l}\text { Free testosterone } \\
(0.6-6.8 \mathrm{pg} / \mathrm{ml})\end{array}$ & $4.4 \pm 2.7$ & $5.4 \pm 2.5$ & $5.5 \pm 2.0$ & 0.121 \\
\hline $\begin{array}{c}\text { DHEA } \\
(44-332 \mu \mathrm{g} / \mathrm{dL})\end{array}$ & $263.7 \pm 117.4$ & $271.9 \pm 126.5$ & $280.7 \pm 132.2$ & 0.852 \\
\hline $\begin{array}{l}\text { Fasting Insulin } \\
(<25 \mu \mathrm{IU} / \mathrm{L})\end{array}$ & $27.9 \pm 8.7$ & $28.9 \pm 8.1$ & $29.8 \pm 10.6$ & 0.711 \\
\hline $\begin{array}{c}\mathrm{Hb} \text { A } 1 \mathrm{c} \\
(<5.7 \%)\end{array}$ & $4.4 \pm 0.6$ & $4.8 \pm 0.7$ & $4.7 \pm 0.8$ & 0.102 \\
\hline $\begin{array}{c}\text { LDL } \\
\text { (up to } 140 \mathrm{mg} / \mathrm{dl} \text { ) }\end{array}$ & $129.6 \pm 27.3$ & $133.6 \pm 32.5$ & $127.6 \pm 28.9$ & 0.691 \\
\hline
\end{tabular}


Table 2. Comparison between pre- and post-study variables in group 1.

\begin{tabular}{cccc}
\hline & Basal levels & Post study & $p$ value \\
\hline BMI & $27.5 \pm 5.2$ & $27.0 \pm 4.5$ & $0.016^{*}$ \\
Ferriman-Gallwey $(\mathrm{F}-\mathrm{G})$ score & $12.0 \pm 7.4$ & $10.74 \pm 6.12$ & $0.003^{*}$ \\
Free testosterone $(0.6-6.8 \mathrm{pg} / \mathrm{ml})$ & $4.4 \pm 2.7$ & $3.9 \pm 2.0$ & $0.003^{*}$ \\
DHEA $(44-332 \mu \mathrm{g} / \mathrm{dL})$ & $263.7 \pm 117.4$ & $221.0 \pm 82.2$ & $0.001^{*}$ \\
Fasting Insulin $(<25 \mu \mathrm{IU} / \mathrm{L})$ & $27.9 \pm 8.7$ & $25.4 \pm 4.7$ & $0.036^{*}$ \\
Hb Alc $(<5.7 \%)$ & $4.4 \pm 0.6$ & $3.8 \pm 0.7$ & $0.000^{*}$ \\
LDL (up to $140 \mathrm{mg} / \mathrm{dl})$ & $129.6 \pm 27.3$ & $127.6 \pm 28.9$ & 0.686 \\
\hline
\end{tabular}

*Significant.

Table 3. The effect of Pioglitazobe on the menstrual irregularities in group 1.

\begin{tabular}{lcccccr}
\hline & & Oligomenorrhea & Amenorrhea & Regular cycles & $\mathrm{X}^{2}$ & $p$ value \\
\hline \multirow{2}{*}{ Before TTT } & $\mathrm{N}$ & 24 & 5 & 6 & & \\
& $\%$ & $68.5 \%$ & $14.2 \%$ & $17.1 \%$ & & \\
\multirow{2}{*}{ After TTT } & $\mathrm{N}$ & 15 & 4 & 16 & 6.733 & $0.035^{*}$ \\
& $\%$ & $42.8 \%$ & $11.4 \%$ & $45.7 \%$ & & \\
\hline
\end{tabular}

${ }^{*}$ Significant.

Table 4. Comparison between pre- and post-study variables in group 2.

\begin{tabular}{cccc}
\hline & Basal levels & Post study & $p$ value \\
\hline BMI & $28.0 \pm 5.1$ & $27.3 \pm 4.5$ & $0.001^{*}$ \\
Ferriman-Gallwey (F-G) score & $11.8 \pm 7.9$ & $12.4 \pm 7.1$ & $0.046^{*}$ \\
Free testosterone $(0.6-6.8 \mathrm{pg} / \mathrm{ml})$ & $5.4 \pm 2.5$ & $5.6 \pm 2.2$ & 0.350 \\
DHEA $(44-332 \mu \mathrm{g} / \mathrm{dL})$ & $271.9 \pm 126.5$ & $353.1 \pm 362.5$ & 0.217 \\
Fasting Insulin $(<25 \mu \mathrm{IU} / \mathrm{L})$ & $28.9 \pm 8.1$ & $31.4 \pm 7.6$ & 0.064 \\
Hb A1c $(<5.7 \%)$ & $4.8 \pm 0.7$ & $4.2 \pm 0.9$ & $0.000^{*}$ \\
LDL (up to $140 \mathrm{mg} / \mathrm{dl})$ & $133.6 \pm 32.5$ & $129.6 \pm 27.3$ & 0.596
\end{tabular}

${ }^{*}$ Significant.

Table 5 shows the effect of Vildagliptin on the menstrual irregularities in group 2, Chi Square test shows no significant change of the rate of oligomenorrhea and amenorrhea i.e. no significant regaining of menstrual cyclicity.

Assessment of the effect of the drug Metformin on the study variables in group 3 (Table 6) using paired $\mathrm{T}$ test shows significant reduction of BMI, Ferriman-Gallwey score, free testosterone level and $\mathrm{Hb}$ alc level. But no significant reduction of DHEA level, Fasting insulin level. Also there is non-significant elevation of LDL level.

Table 7 shows the effect of Metformin on the menstrual irregularities in group 3, Chi Square test shows significant reduction of oligomenorrhea and amenorrhea i.e. significant regaining of menstrual cyclicity.

The following Figures 1-9 show comparison of the change of study variables between the study groups. 


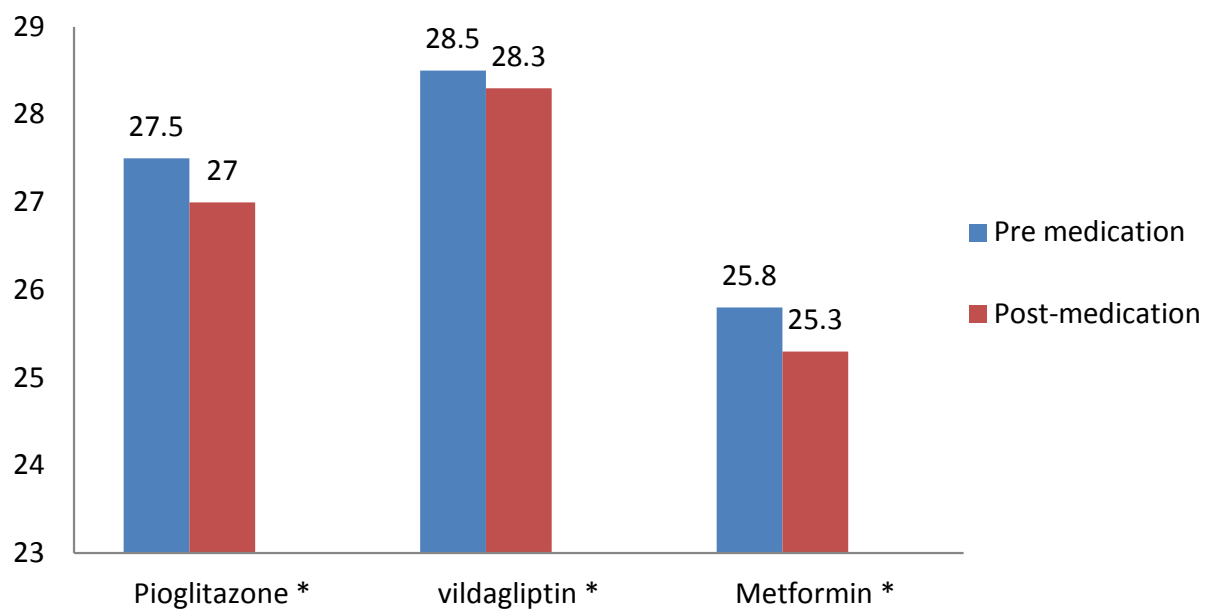

Figure 1. BMI. ${ }^{\star}$ Significant.

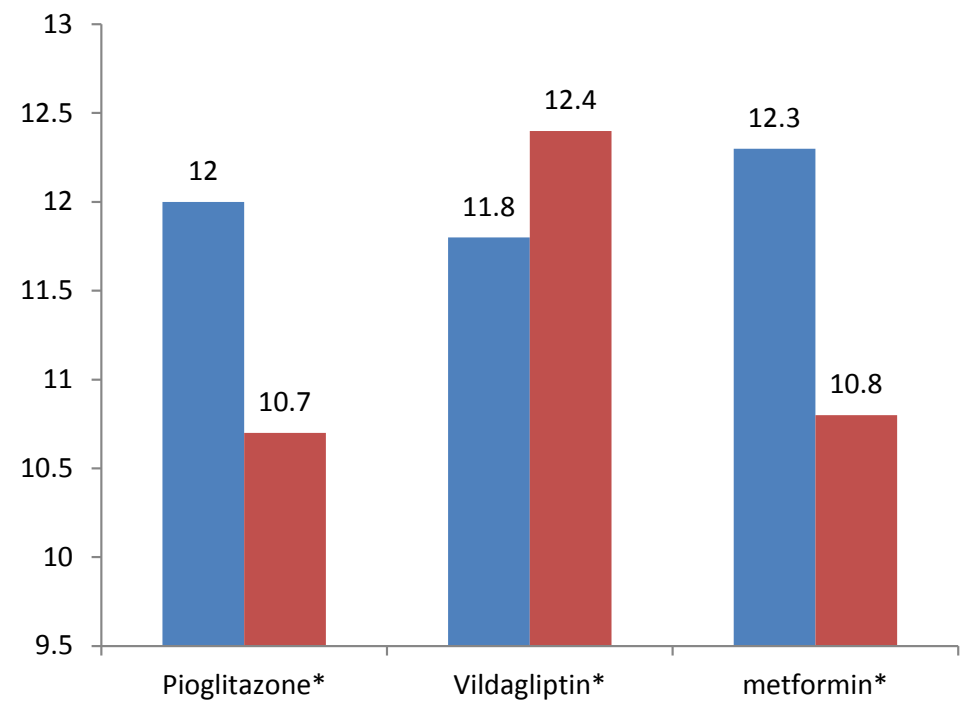

Figure 2. Ferriman-Gallwey score. *Significant.

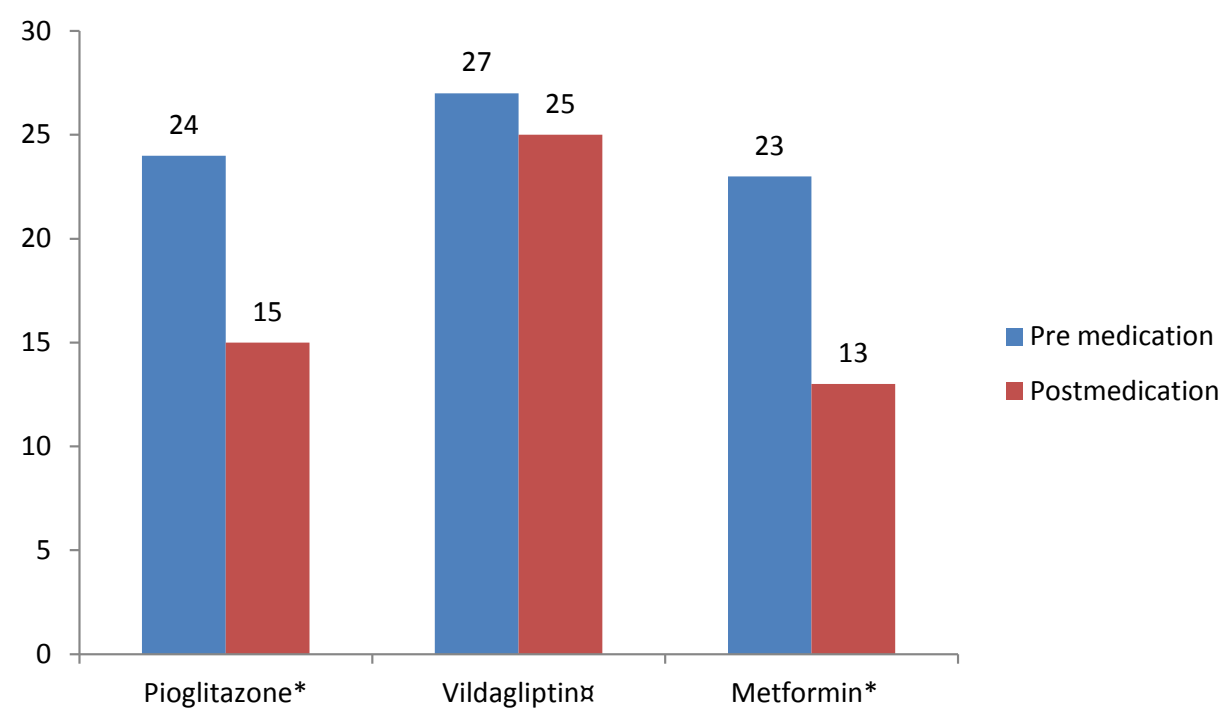

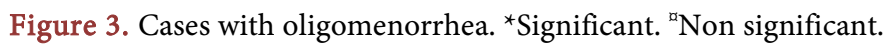




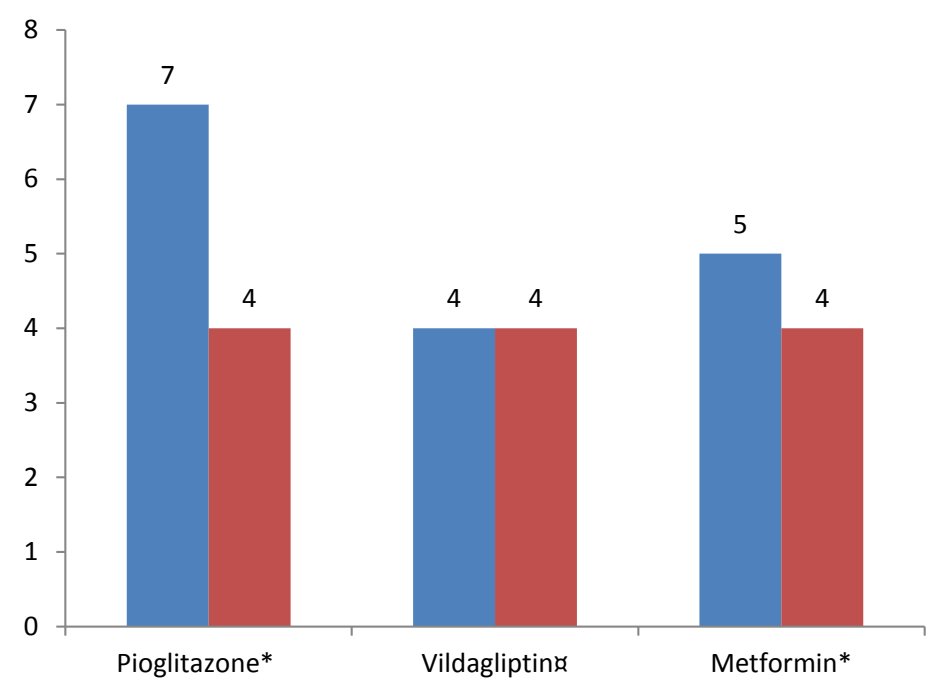

- Pre medication

- Postmedication

Figure 4. Cases with amenorrhea. ${ }^{\star}$ Significant. ${ }^{x}$ Non significant.

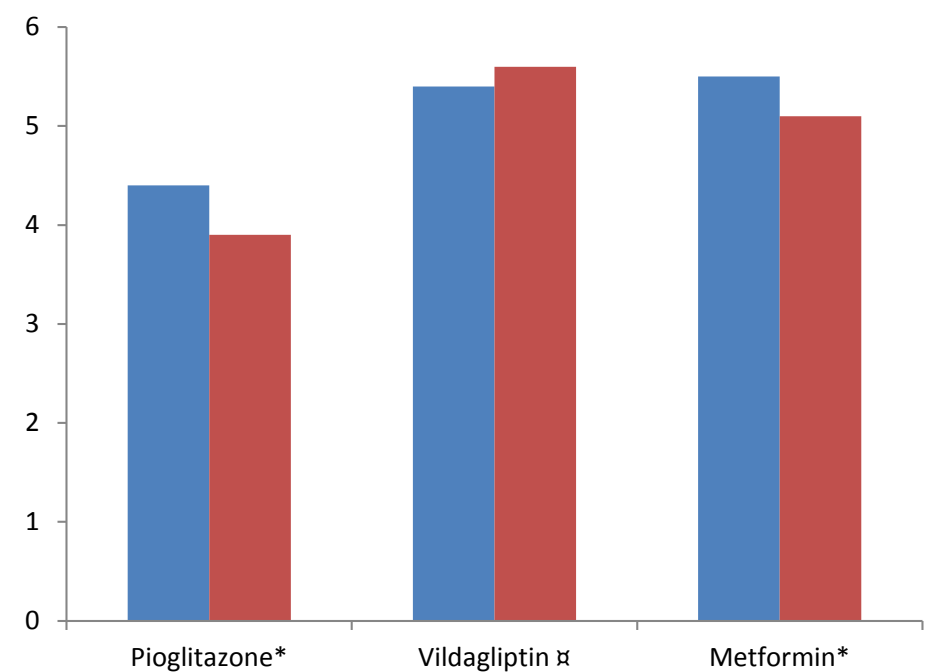

Figure 5. Free testosterone “pg/ml”. * Significant. "Non significant.

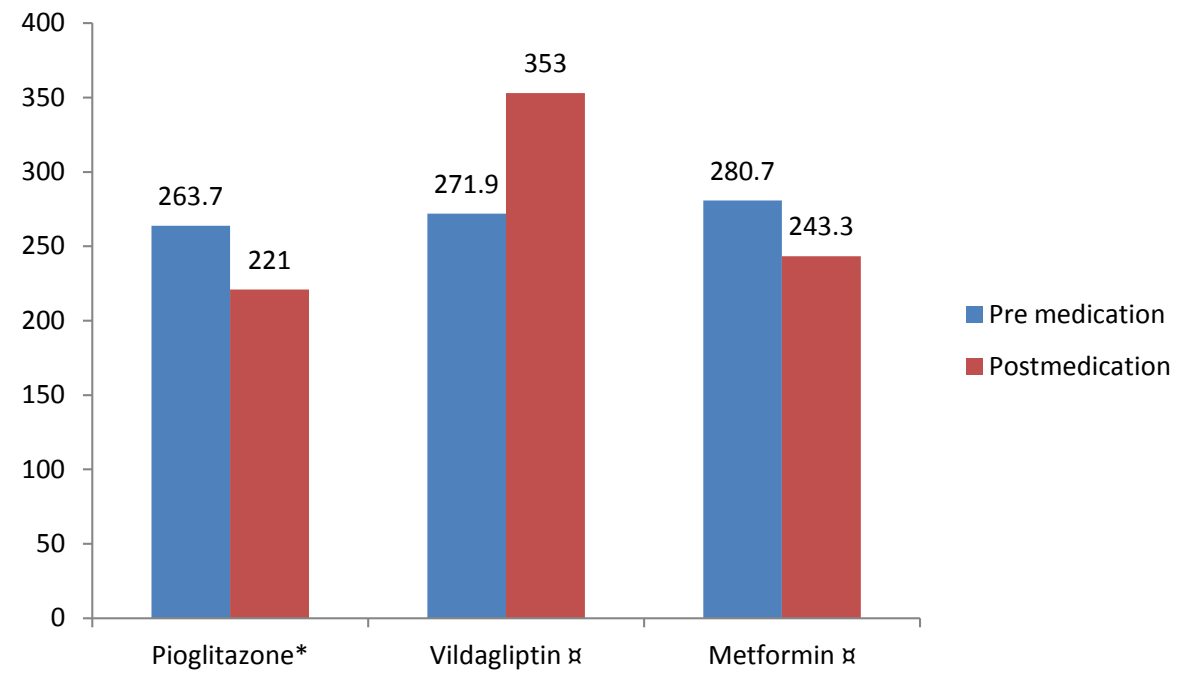

Figure 6. DHEA “ $\mu$ g/dl”. ${ }^{\star S i g n i f i c a n t . ~}{ }^{a}$ Non significant. 


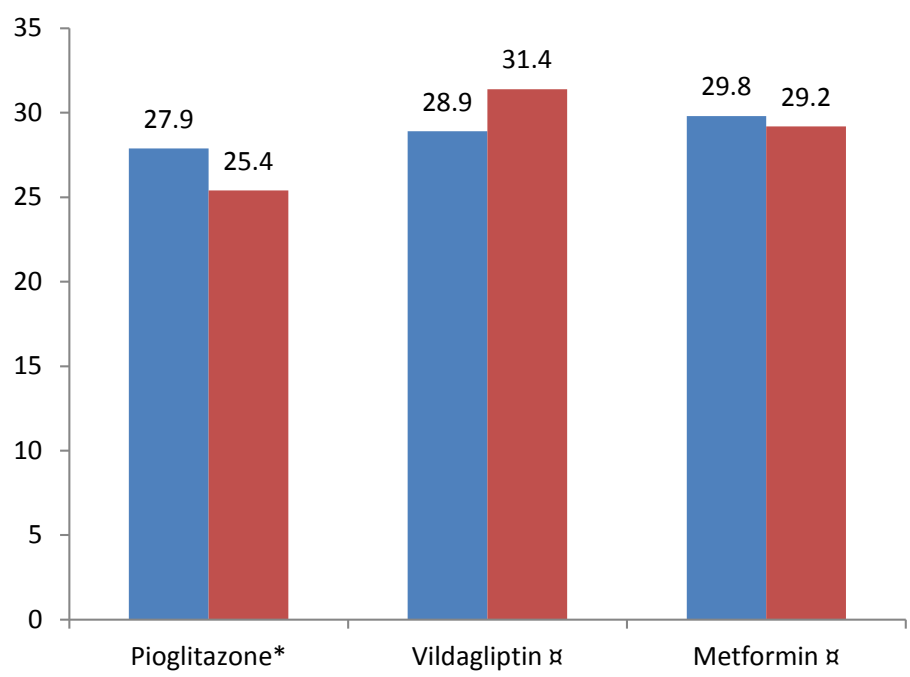

- Pre medication

- Postmedication

Figure 7. Fasting insulin “ $\mu$ IU/L”. *Significant. "Non significant.

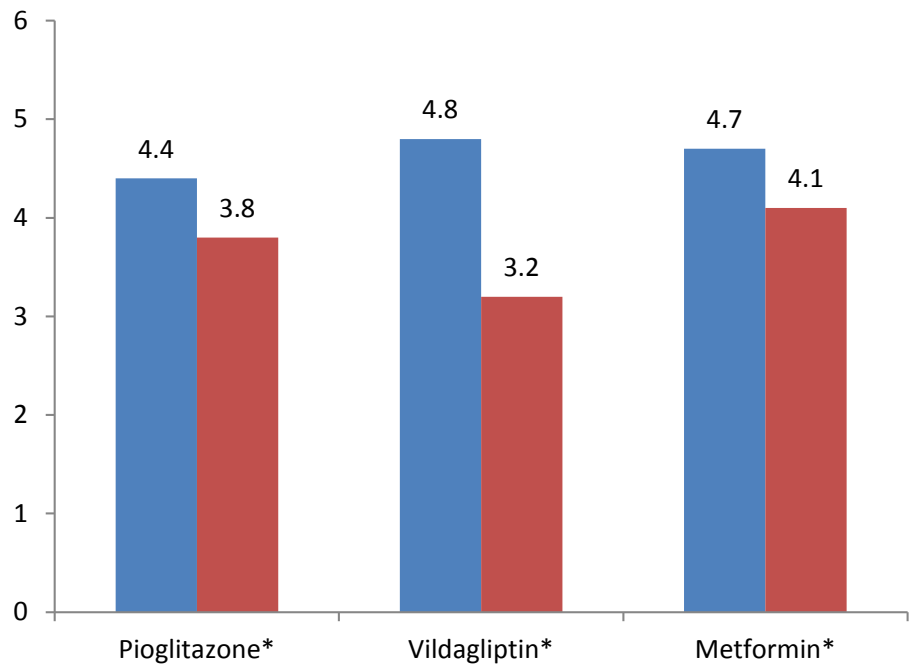

Pre medication

- Postmedication

Figure 8. Hb A1c “gm\%”. *Significant.

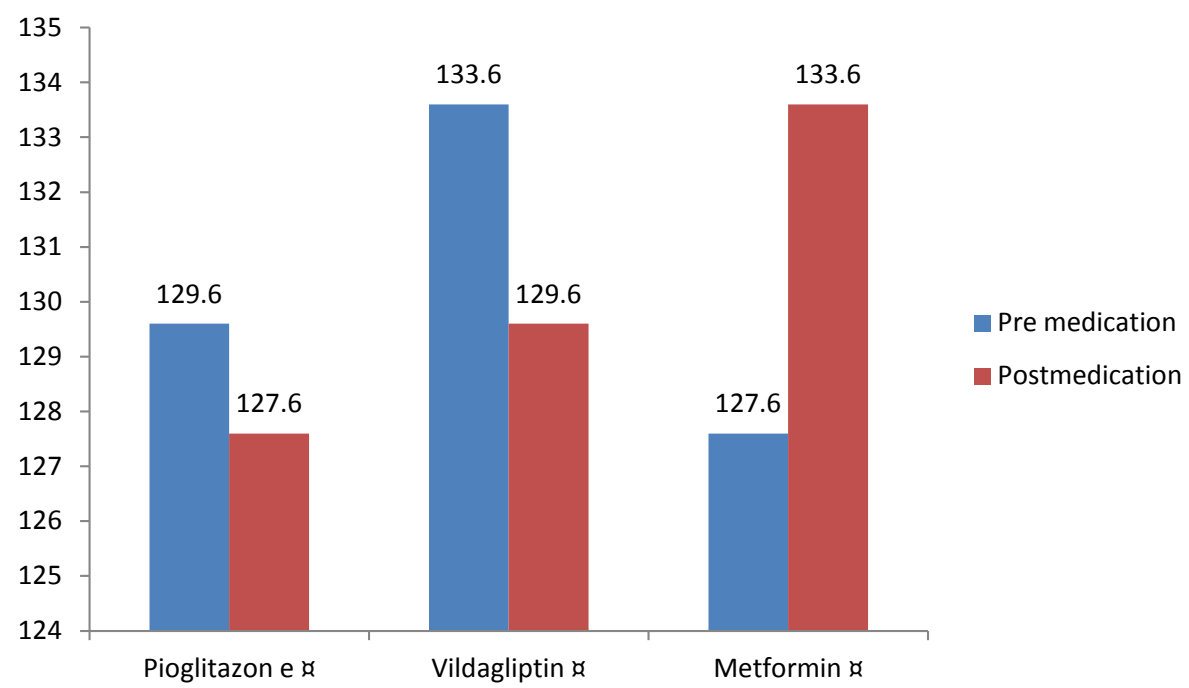

Figure 9. LDL “mg/dl”. "Non significant. 
Table 5. The effect of Vildagliptin on the menstrual irregularities in group 2.

\begin{tabular}{ccccccc}
\hline & & Oligomenorrhea & Amenorrhea & Regular cycles & $\mathrm{X}^{2}$ & $p$ value \\
\hline \multirow{2}{*}{ Before TTT } & $\mathrm{N}$ & 27 & 4 & 4 & & \\
& $\%$ & $77.1 \%$ & $11.4 \%$ & $11.4 \%$ & & \\
\multirow{2}{*}{ After TTT } & $\mathrm{N}$ & 25 & 4 & 6 & 0.477 & 0.788 \\
& $\%$ & $71.4 \%$ & $11.4 \%$ & $17.1 \%$ & & \\
\hline
\end{tabular}

Table 6. Comparison between pre- and post-study variables in group 3.

\begin{tabular}{cccc}
\hline & Basal levels & Post study & $p$ value \\
\hline BMI & $25.8 \pm 5.7$ & $25.3 \pm 5.0$ & $0.010^{*}$ \\
Ferriman-Gallwey $(\mathrm{F}-\mathrm{G})$ score & $12.3 \pm 7.4$ & $10.8 \pm 5.5$ & $0.002^{*}$ \\
Free testosterone $(0.6-6.8 \mathrm{pg} / \mathrm{ml})$ & $5.5 \pm 2.0$ & $5.1 \pm 1.3$ & $0.034^{*}$ \\
DHEA $(44-332 \mu \mathrm{g} / \mathrm{dL})$ & $280.7 \pm 132.2$ & $243.3 \pm 103.5$ & 0.057 \\
Fasting Insulin $(<25 \mu \mathrm{IU} / \mathrm{L})$ & $29.8 \pm 10.6$ & $29.23 \pm 9.5$ & 0.645 \\
Hb Alc $(<5.7 \%)$ & $4.7 \pm 0.8$ & $4.1 \pm 0.7$ & $0.000^{\star}$ \\
LDL (up to $140 \mathrm{mg} / \mathrm{dl})$ & $127.6 \pm 28.9$ & $133.6 \pm 32.5$ & 0.374
\end{tabular}

*Significant.

Table 7. The effect of Metformin on the menstrual irregularities in group 3.

\begin{tabular}{lcccccc}
\hline & & Oligomenorrhea & Amenorrhea & Regular cycles & $\mathrm{X}^{2}$ & $p$ value \\
\hline \multirow{2}{*}{ Before TTT } & $\mathrm{N}$ & 23 & 7 & 5 & & \\
& $\%$ & $65.7 \%$ & $20.0 \%$ & $14.2 \%$ & & \\
After TTT & $\mathrm{N}$ & 13 & 4 & 18 & 10.944 & $0.004^{*}$ \\
& $\%$ & $37.1 \%$ & $11.4 \%$ & $51.4 \%$ & &
\end{tabular}

*Significant.

\section{Discussion}

The primary objective of the study is to evaluate other oral hypoglycemic medications; specially the new ones in the management of PCOS patients as alternatives to the standard medication used for this purpose Metformin. We used many indices to assess the improvement in the clinical and metabolic condition of the patients.

Pioglitazobe in the study group 1 patients showed a significant reduction of BMI, Ferriman-Gallwey score, free testosterone level, DHEA level, Fasting insulin level and $\mathrm{Hb}$ alc level, and also significant reduction of menstrual irregularities. But non significant reduction of LDL level is noticed. When compared to Metformin in the control group 3 in which there were significant reduction of BMI, Ferriman-Gallwey score, free testosterone level and $\mathrm{Hb}$ a1c level. But no significant reduction of DHEA level, Fasting insulin level. Also there is non-significant elevation of LDL level. This means that the clinical and metabolic effect of Pioglitazobe is better than Metformin in PCOS patients.

On the contrary there were disappointing results of the new drug Vildagliptin in group 2, the patients in this group showed significant reduction of BMI and $\mathrm{Hb}$ a1c 
level only. Non significant effect on menstrual irregularities and non significant reduction of LDL level is noticed. But there is elevation of Ferriman-Gallwey score, free testosterone level, DHEA level and Fasting insulin level. This can be explained by that Vildagliptin is a selective, reversible, competitive inhibitor of dipeptidyl peptidase- 4 (DPP4). DPP4 is involved in the inactivation of many neuropeptides, cytokines, chemokines, and gastrointestinal hormones. Two important hormones involved in glucose homeostasis and inactivated by DPP4 are glucose-dependent insulinotropic polypeptide (GIP) and GLP-1. GIP and GLP-1 are incretins, which are hormones released from the gut that stimulate insulin secretion in response to food intake. GLP-1, the most potent insulinotropic hormone, enhances glucose-dependent secretion of insulin from pancreatic $\beta$-cells and inhibits glucagon secretion. Inhibition of DPP4, results in increased levels of active GLP-1 and subsequent enhancement of insulin release i.e. Vildagliptin increases insulin release rather than improves insulin sensitivity which explains most of the disappointing results of the group 2 in the current study.

To the best of our knowledge there was only one study on Vildagliptin in PCOS patients. ZHAO Xiaolan and FENG Lin [19] published this study in which they compared 2 groups; a study group received Vildagliptin in combination with Metformin for 6 months versus a control group received Metformin only. They concluded that Metformin combine with Vildagliptin can effectively improve the levels of endocrine,sugar and fat metabolism in patients of polycystic ovary syndrome (PCOS) with abnormal glucose metabolism, which is effective and safe. The contradiction with our results can be explained by that they used the Vildagliptin in combination with Metformin.

\section{Limitation}

The Limitation of this study is the small sample size.

\section{Conclusion}

Pioglitazobe is an effective and safe alternative to Metformin in the management of PCOS patient although further studies including larger number of patients should be done while Vildagliptin should be omitted for use in PCOS patients.

\section{Declaration of Funding}

This study was not funded.

\section{Declaration of Financial/Other Relationships}

The authors of this manuscript have no relevant financial relationships to disclose.

\section{References}

[1] Hu, L., Shen, H., Wu, Q.F., Tian, L. and Hu, M.H. (2014) Treatment of Polycystic Ovarian Syndrome with Insulin Resistance by Insulin-Sensitizer. Clinical \& Experimental Obstetrics \& Gynecology, 41, 288-292.

[2] Valsamakis, G., Lois, K., Kumar, S. and Mastorakos, G. (2013) Metabolic and Other Effects of Pioglitazone as an Add-On Therapy to Metformin in the Treatment of Polycystic Ovary Syndrome (PCOS). Hormones, 12, 363-378. 
[3] Cho, L.W., Kilpatrick, E.S., Keevil, B.G., Coady, A.M. and Atkin, S.L. (2009) Effect of Metformin, Orlistat and Pioglitazone Treatment on Mean Insulin Resistance and Its Biological Variability in Polycystic Ovary Syndrome. Clinical Endocrinology, 70, 233-237. https://doi.org/10.1111/j.1365-2265.2008.03309.x

[4] Katsiki, N. and Hatzitolios, A.I. (2010) Insulin-Sensitizing Agents in the Treatment of Polycystic Ovary Syndrome: An Update. Current Opinion in Obstetrics and Gynecology, 22, 466-476. https://doi.org/10.1097/GCO.0b013e32833e1264

[5] Ziaee, A., Oveisi, S., Abedini, A., Hashemipour, S., Karimzadeh, T. and Ghorbani, A. (2012) Effect of Metformin and Pioglitazone Treatment on Cardiovascular Risk Profile in Polycystic ovary Syndrome. Acta Medica Indonesiana, 44, 16-22.

[6] Ibanez, L., Lopez-Bermejo, A., Diaz, M., Enriquez, G., Del Rio, L. and De Zegher, F. (2010) Low-Dose Pioglitazone, Flutamide, Metformin plus an Estro-Progestagen for Non-Obese Young Women with Polycystic Ovary Syndrome: Increasing Efficacy and Persistent Safety over 30 Months. Gynecological Endocrinology, 26, 869-873.

https://doi.org/10.3109/09513590.2010.487589

[7] Roe, A., Hillman, J., Butts, S., Smith, M., Rader, D., Playford, M., et al. (2014) Decreased Cholesterol Efflux Capacity and Atherogenic Lipid Profile in Young Women with PCOS. Journal of Clinical Endocrinology \& Metabolism, 99, 2013-3918. https://doi.org/10.1210/jc.2013-3918

[8] Du, Q., Wang, Y.J., Yang, S., Wu, B., Han, P. and Zhao, Y.Y. (2012) A Systematic Review and Meta-Analysis of Randomized Controlled Trials Comparing Pioglitazone versus Metformin in the Treatment of Polycystic Ovary Syndrome. Current Medical Research and Opinion, 28, 723-730. https://doi.org/10.1185/03007995.2012.681636

[9] Li, X.J., Yu, Y.X., Liu, C.Q., Zhang, W., Zhang, H.J., Yan, B., et al. (2011) Metformin vs Thiazolidinediones for Treatment of Clinical, Hormonal and Metabolic Characteristics of Polycystic Ovary Syndrome: A Meta-Analysis. Clinical Endocrinology, 74, 332-339. https://doi.org/10.1111/j.1365-2265.2010.03917.x

[10] Haydardedeoglu, B., Simsek, E., Kilicdag, E.B. and Bagis, T. (2009) Metabolic and Endocrine Effects of Metformin and Metformin plus Cyclic Medroxyprogesterone Acetate in Women with Polycystic Ovary Syndrome. International Journal of Gynecology \& Obstetrics, 105, 32-35. https://doi.org/10.1016/j.ijgo.2008.11.039

[11] Ahren, B., Foley, J.E. and Bosi, E. (2011) Clinical Evidence and Mechanistic Basis for Vildagliptin's Action When Added to Metformin. Diabetes, Obesity and Metabolism, 13, 193203. https://doi.org/10.1111/j.1463-1326.2010.01321.x

[12] Schweizer, A., Couturier, A., Foley, J.E. and Dejager, S. (2007) Comparison between Vildagliptin and Metformin to Sustain Reductions in $\mathrm{HbA}(1 \mathrm{c})$ over 1 Year in Drug-Naive Patients with Type 2 Diabetes. Diabetic Medicine, 24, 955-961.

https://doi.org/10.1111/j.1464-5491.2007.02191.x

[13] Garber, A.J., Foley, J.E., Banerji, M.A., Ebeling, P., Gudbjornsdottir, S., Camisasca, R.P., et al. (2008) Effects of Vildagliptin on Glucose Control in Patients with Type 2 Diabetes Inadequately Controlled with a Sulphonylurea. Diabetes, Obesity and Metabolism, 10, 10471056. https://doi.org/10.1111/j.1463-1326.2008.00859.x

[14] Karagiannis, T., Paschos, P., Paletas, K., Matthews, D.R. and Tsapas, A. (2012) Dipeptidyl Peptidase-4 Inhibitors for Treatment of Type 2 Diabetes Mellitus in the Clinical Setting: Systematic Review and Meta-Analysis. BMJ, 12, e1369. https://doi.org/10.1136/bmj.e1369

[15] Schweizer, A., Dejager, S., Foley, J.E. and Kothny, W. (2011) Assessing the General Safety and Tolerability of Vildagliptin: Value of Pooled Analyses from a Large Safety Database versus Evaluation of Individual Studies. Vascular Health and Risk Management, 7, 49-57. https://doi.org/10.2147/VHRM.S16925

[16] Geller, D.H., Pacaud, D., Gordon, C.M. and Misra, M. (2011) State of the Art Review: 
Emerging Therapies: The Use of Insulin Sensitizers in the Treatment of Adolescents with Polycystic Ovary Syndrome (PCOS). International Journal of Pediatric Endocrinology, 26, 1687-9856. https://doi.org/10.1186/1687-9856-2011-9

[17] DeUgarte, C.M., Woods, K.S., Bartolucci, A.A. and Azziz, R. (2006) Degree of Facial and Body Terminal Hair Growth in Unselected Black and White Women: Toward a Populational Definition of Hirsutism. Journal of Clinical Endocrinology \& Metabolism, 91, 13451350. https://doi.org/10.1210/jc.2004-2301

[18] Faul, F., Erdfelder, E., Buchner, A. and Lang, A.-G. (2013) Statistical Power Analyses Using $\mathrm{G}^{\star}$ Power 3.1: Tests for Correlation and Regression Analyses. Behavior Research Methods, 41, 1149-1160. https://doi.org/10.3758/BRM.41.4.1149

[19] Zhao, X.L. and Feng, L. (2016) Clinical Efficacy of Metformin Combined with Vildagliptin in the Treatment of Polycystic Ovary Syndrome with Abnormal Glucose Metabolism. The Chinese Journal of Clinical Pharmacology, 6.

Submit or recommend next manuscript to SCIRP and we will provide best service for you:

Accepting pre-submission inquiries through Email, Facebook, LinkedIn, Twitter, etc. A wide selection of journals (inclusive of 9 subjects, more than 200 journals)

Providing 24-hour high-quality service

User-friendly online submission system

Fair and swift peer-review system

Efficient typesetting and proofreading procedure

Display of the result of downloads and visits, as well as the number of cited articles

Maximum dissemination of your research work

Submit your manuscript at: http://papersubmission.scirp.org/

Or contact ojog@scirp.org 